\title{
Characterization of Metal Matrix Composites Reinforced with Carbon Nanotubes by High Resolution Transmission Electron Microscopy
}

\author{
Cesar A. Isaza Mํ, J. M. Meza ${ }^{1}$, J. E. Ledezma Sillas ${ }^{2}$ and J. M. Herrera-Ramirez ${ }^{2}$. \\ 1. Universidad Nacional de Colombia, Facultad de Minas, Departamento de Materiales y Minerales $\mathrm{Cl}$ \\ 75 No 79A 51, Colombia. \\ 2. Centro de Investigacion en Materiales Avanzados (CIMAV), Laboratorio Nacional de \\ Nanotecnologia, Miguel de Cervantes 120, Chihuahua, Chih., Mexico.
}

Since their discovery by Ijiima [1], carbon nanotubes have been considered as an ideal reinforcing material to improve the mechanical properties in polymeric, ceramic and metallic materials [2-4]. The need to find high-strength lightweight materials in transportation industries has driven the development of new materials and manufacturing methods to reduce $\mathrm{CO}_{2}$ emissions into the atmosphere.

Recently, a new manufacturing process for the production of metal matrix composites reinforced with carbon nanotubes, known as sandwich technique, has been proposed [5-7]. This technique produces materials comprised of a metallic matrix and banded structured-layers of multiwalled carbon nanotubes (MWCNTs).

The composites fabricated, both pure aluminum and AZ31 magnesium reinforced with MWCNTs, were characterized and studied by FESEM, TEM and HRTEM techniques for identifying the interaction between aluminum or magnesium matrix and MWCNTs. Figure 1a shows the MWCNTs used in this study, which have outer diameters of 10-40 nm and inner diameters of 10-20 nm, with a length of 30$50 \mu \mathrm{m}$. Some imperfections, including variable numbers of carbon layers and partial interior filling, amorphous carbon, and "bamboo" defects, are showed. These defects consist of several transverse, internal walls segmenting the interior of MWCNTs into independent pods or isolated volumes.

In both aluminum and magnesium composites a good dispersion of the MWCNTs into the metal matrix is clearly seen (Figures $1 \mathrm{~b}$ and 1c), which proves the success of the sandwich technique to synthesize these kind of composites. Figures 2 shows TEM and HRTEM images for both composites, where the MWCNTs can be observed embedded into the aluminum matrix (Figure 2a) and the magnesium alloy matrix (Figure 2b). The details in Figure 2 let see a good and homogeneous interface between both metal matrices and the MWCNTs, with no evidence of the formation of carbides or any other phase.

References:

[1] S. Iijima, Nature 354 (1991), p. 56.

[2] S.C. Tjong, Materials Science and Engineering: R: Reports 74 (2013), p. 281.

[3] M. Estili, Y. Sakka, Science and Technology of Advanced Materials 15 (2014), p. 064902.

[4] Y. Liu, S. Kumar, ACS Applied Materials \& Interfaces 6 (2014), p. 6069.

[5] Cesar A. Isaza Merino et al, Journal of Composites Materials (2016) 0021998316658784.

[6] C. Isaza, G. Sierra, J. Meza, Journal of Manufacturing Science and Engineering 138 (2016), 024501.

[7] Cesar A. Isaza Merino et al, Journal of Alloys and Compounds (2016) in press. 


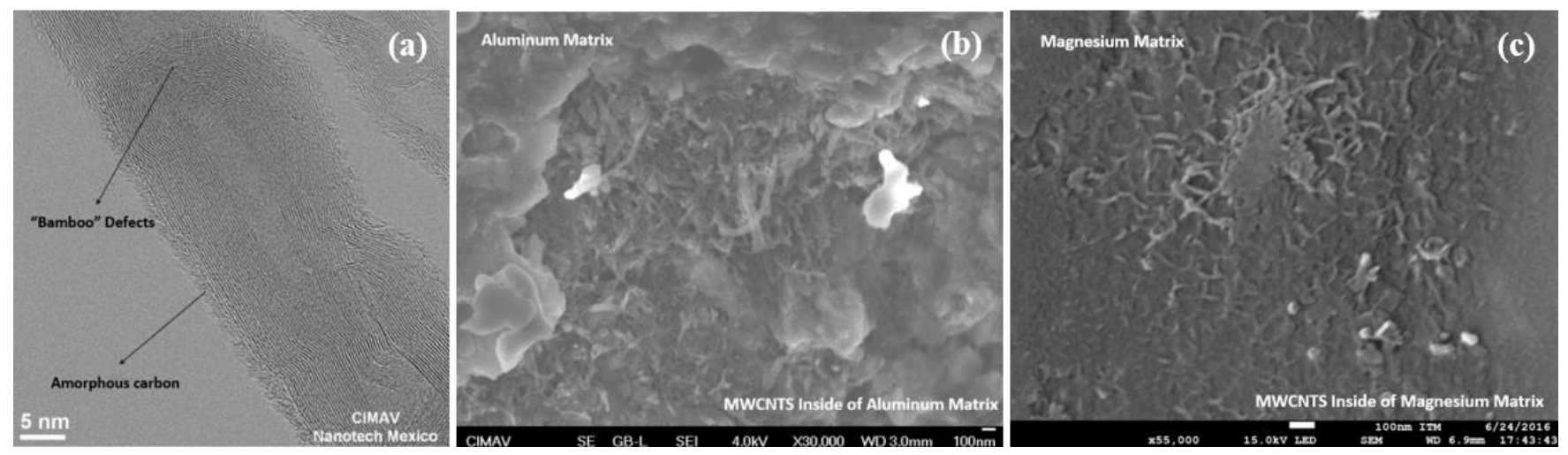

Figure 1. (a) TEM image of the MWCNTs used in this study. FESEM images of (b) Al/MWCNTs and (c) AZ31 Mg/MWCNTs composites.

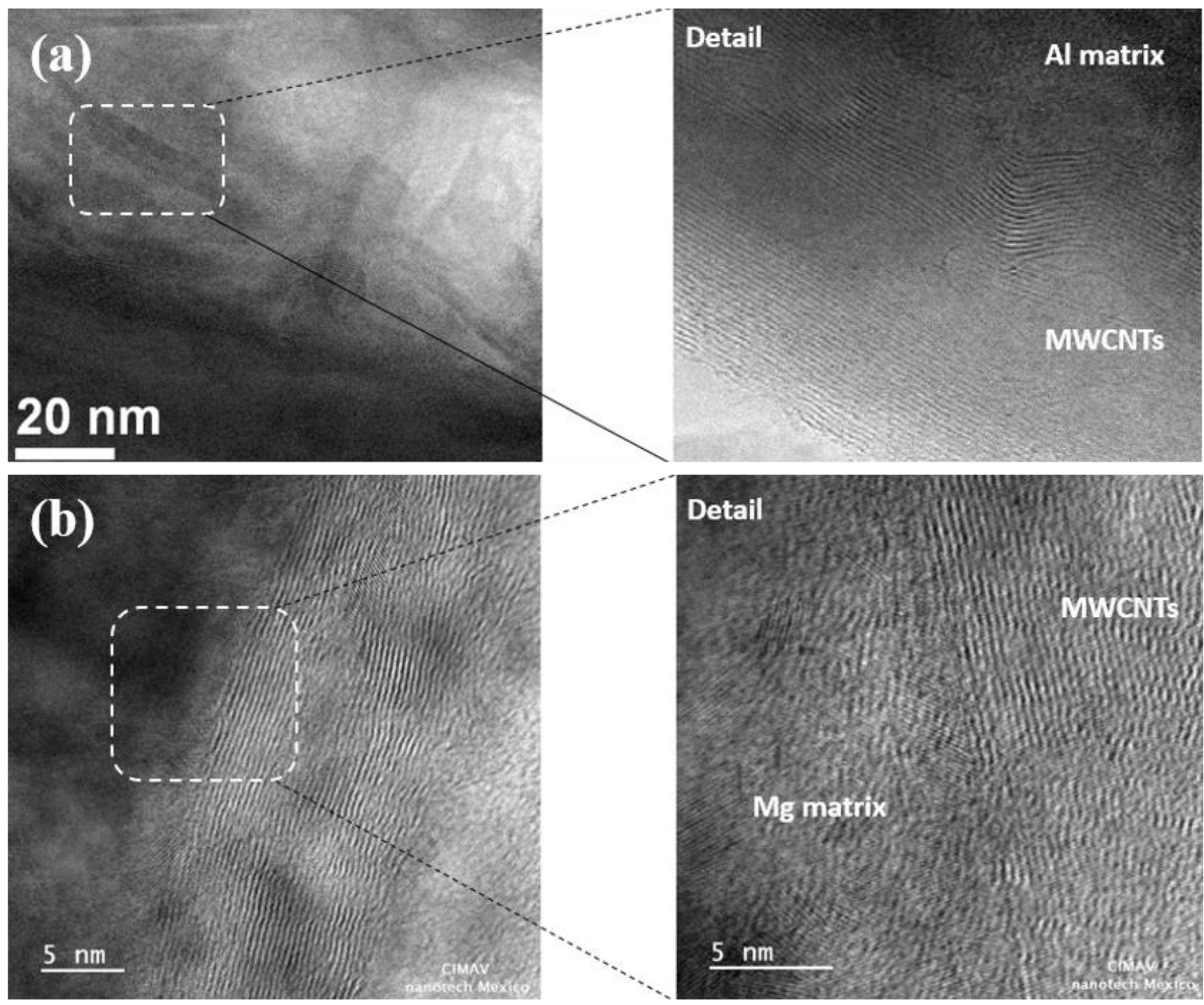

Figure 2. TEM images of (a) pure $\mathrm{Al}$ and (b) AZ31 Mg reinforced with MWCNTs. 